\title{
CHEMICAL CHARACTERIZATION AND THERMAL COMFORT PROPERTIES OF COTTON FINISHED WITH PHASE CHANGE MATERIALS AND ANTIMICROBIAL AGENTS
}

\author{
FABIO A. P. SCACCHETTI ${ }^{*}$ and GRAÇA. M. B. SOARES** \\ "Department of Textile Engineering, Federal University of Technology - Paraná (UTFPR), \\ 86812-460 Apucarana, Brazil \\ ${ }^{* *}$ Center for Textile Science and Technology, Department of Textile Engineering, University of Minho, \\ 4800-058 Guimarães, Portugal \\ ๔Corresponding author: Fabio A.P. Scacchetti, fabioscacchetti@utfpr.edu.br
}

Received September 18, 2018

\begin{abstract}
The expectations regarding the functional characteristics and performance of textile products have been steadily increasing. In this sense, multifunctional materials with thermoregulatory and antimicrobial properties were developed using different finishing strategies. For this purpose, through finishing processes, the application of microcapsules of phase change materials, mPCM, combined with different antimicrobial agents of natural origin, was carried out. Specifically, zeolites doped with silver, composites of chitosan with zeolites doped with silver, and $\mathrm{TiO}_{2}$, in different application combinations, were used. The resulting multifunctional cotton materials were characterized and their performance was evaluated in terms of thermal comfort, stationary properties and moisture management. The statistical analysis of the results has indicated that the thermal properties underwent changes related to the introduction of mPCM in the treated samples, but the antimicrobial finishing also had an effect on the results obtained. As expected, the finishes contributed to a decrease in the permeability of the samples studied, however, without compromising the breathability of the materials. It was concluded that the best combination of finishes was achieved with the application of mPCM combined with the chitosan film with silver doped zeolites.
\end{abstract}

Keywords: cotton, thermal conductivity, thermal resistance, thermal absorptivity, permeability, mPCM

\section{INTRODUCTION}

The comfort conferred by textile materials, although of recognized importance and deeply studied, is difficult to describe. Normally, it refers to the contribution to the physical, physiological and psychological harmony between the human being and the environment that surrounds him/her. The subjective perception of several important sensations depends on the phenomena of moisture management and heat transfer through the material, as they influence the user's well-being. ${ }^{1-3}$

The properties of fibers and yarns, the structure of fabrics and the finishing treatments to which they are subjected influence the measurement of the thermal and permeability properties of the materials. ${ }^{3-5}$ Thermal conductivity, resistance and absorptivity are parameters that measure the thermal comfort of textiles. The concept of hot-cold sensation at first contact with the surface was first pointed by Kawabata and Akagi, ${ }^{6}$ and, later, objectified by Hes and Dolezal, ${ }^{7}$ who introduced the quantification of this property, which they called "thermal absorptivity".

The application of phase change materials presents interest in increasing the feeling of freshness in the use of sportswear in a warmer climate. In fact, phase change materials alter the properties of the material in order to decrease its thermal resistance, increasing the thermal conductivity and absorptivity. ${ }^{8,9}$ However, their performance also depends on the equilibrium achieved with other properties, such as the permeability to both air and water vapor., ${ }^{3,10-12}$ The effect of the incorporation of phase change materials to improve the thermal comfort of textiles has been extensively studied. ${ }^{11,13-16}$ However, the effect of other finishing agents is 
rarely considered in this evaluation, especially of antimicrobial agents.

The application of metallic nanoparticles in textiles has been studied mainly to intensify the antimicrobial activity, the challenge being divided between better adhesion and durability in natural fibers. ${ }^{17-21}$ On the other hand, natural polymers, such as chitosan, have attracted much attention, mainly for two reasons: the first one refers to the fact that it is biodegradable and biocompatible, besides having antimicrobial properties; the second one is related to its ability to complex metal ions, which have been used to improve its bioactivity. ${ }^{22-25}$

Therefore, considering the commercial interest in the development of textile materials combining antimicrobial properties with comfort characteristics, cotton fabrics with these functional characteristics have been developed using different finishing strategies. As a result, the present study describes some new approaches to the multifunctionalization of cotton. Moreover, to the best of our knowledge, this combination of products has never been properly analyzed in textile finishing.

The textiles obtained, with antimicrobial activity, were characterized by differential scanning calorimetry and infrared thermography, and they were evaluated regarding the thermoregulation behaviour. The results indicated that the thermal comfort of the materials was improved in all the treated samples, when compared with the untreated cotton. Generally speaking, the combination of finishes that was performed was beneficial in terms of thermal comfort. Explicitly, a lower impact on the permeability to air and water vapor was achieved in the finishes combining MPCM with the chitosan film with silver doped zeolites, suggesting that these are the most interesting options among the tested ones for the development of these materials.

\section{EXPERIMENTAL}

\section{Materials}

The samples utilized were cotton fabrics provided by Textile Belém, Brazil, $585 \mathrm{~g} / \mathrm{m}^{2}$, with 47 and 17 threads/cm (warp and weft density). The samples were treated, in all the processes, with microcapsules of PCM supplied by Micrópolis Devan (Portugal), a micro-encapsulated paraffin: $85-90 \mathrm{wt} \%$ PCM and 10$15 \mathrm{wt} \%$ polymer shell melamine-formaldehyde (MF). The samples were treated in combination with the nanoparticles of titanium dioxide $\left(\mathrm{TiO}_{2} \mathrm{NP}\right.$, Aeroxide, P25), purchased from Quimidroga (Spain), or with zeolites doped with silver (SZ) provided by the Department of Physics of the School of Engineering of the University of Minho, besides the chitosan, for some applications (320 Mw, viscosity $800 \mathrm{cps})$, Chitoclear® 42030, purchased from Primex (Iceland).

\section{Preparation of finishing materials and processes}

Table 1 describes the samples and their conditions of application in terms of the finishing formulation used. All the finishes were applied using the pad-drycure method in a Foulard Roaches $(4 \mathrm{bar}, 6 \mathrm{~m} / \mathrm{min}$, pick-up 90\%). Then, the samples were dried at $100{ }^{\circ} \mathrm{C}$ for 3 minutes and crosslinked at $140{ }^{\circ} \mathrm{C}$ for 2 minutes. Finally, they were rinsed with abundant water and air dried.

\section{Sample characterization}

The functionalized fabrics were characterized regarding their morphology and distribution of the compounds on the surface. The equipment used to obtain the images was an ultra-high-resolution fieldemission Scanning Electron Microscope (FEG-SEM), NOVA 200 Nano SEM, (FEI Company, Oregon, USA). The analyses were performed at high resolution, after coating the samples with a thin layer of palladium gold.

Attenuated Total Reflectance Fourier Transform (ATR-FTIR) spectroscopy was used to study the functionalized cotton fabrics. Their infrared spectra were recorded on an Avatar 360 spectrophotometer (Madison, EUA), with 60 scans at a resolution of 16 $\mathrm{cm}^{-1}$.

Table 1

Description of samples and application conditions

\begin{tabular}{cll}
\hline Sample & \multicolumn{1}{c}{ Finishing composition } & \multicolumn{1}{c}{ Application conditions } \\
\hline A & Not treated & - \\
B & mPCM & $300 \mathrm{~g} / \mathrm{L} \mathrm{PCM}$ \\
C & mPCM and $\mathrm{TiO}_{2} \mathrm{NP}$ & $300 \mathrm{~g} / \mathrm{L} \mathrm{PCM}$ and $6 \% \mathrm{TiO}_{2} \mathrm{NP}(\mathrm{w} / \mathrm{w})$ \\
$\mathrm{D}$ & mPCM and $\mathrm{SZ}$ & $300 \mathrm{~g} / \mathrm{L} \mathrm{PCM}$ and $2.5 \% \mathrm{SZ}(\mathrm{w} / \mathrm{w})$ \\
$\mathrm{E}$ & mPCM, chitosan film-SZ & $300 \mathrm{~g} / \mathrm{L} \mathrm{PCM}, 250 \mathrm{~g} / \mathrm{L} \mathrm{chitosan}(0.2 \%)$ and $2.5 \% \mathrm{SZ}(\mathrm{w} / \mathrm{w})$ \\
F & mPCM and composites of chitosan-SZ & $300 \mathrm{~g} / \mathrm{L} \mathrm{PCM}$ and $500 \mathrm{~g} / \mathrm{L} \mathrm{NP}$ of chitosan-SZ \\
\hline
\end{tabular}




\section{Antimicrobial evaluation}

The antimicrobial activity of the developed samples was analyzed in detail and was previously reported by our group. ${ }^{26-28}$ All the samples studied in the present work have proven activity against Escherichia coli ATCC $^{\circledR} 25922^{\mathrm{TM}}$, Staphylococcus aureus AATCC $^{\circledR}$ $6538^{\mathrm{TM}}$, Candida albicans ATCC ${ }^{\circledR}$ 10231TM and Trichophyton rubrum (a clinical isolate of superficial dermatophytosis FF9).

\section{Evaluation of properties related to the thermal comfort of materials}

The thermal conductivity, thermal resistance and thermal absorptivity of the samples were measured with Alambeta equipment. The permeability to air was determined using a Textest FX 3300 Tester, in accordance with ISO 9237:1995 standard method. All the tests were performed at the same pressure, specifically, $100 \mathrm{PA}$. The permeability to water vapor was tested using Labthink TSY-W1 equipment, following the test procedure described in BS 7209:1990.

For each of the measured parameters, the tests were repeated 30 times, randomly choosing different parts of the samples. The test samples had been previously stored under standard atmosphere. The number of tests, 30 for each variable studied, was defined to ensure that, in accordance with the central limit theorem, the averages of the samples randomly drawn from each population followed a normal distribution. ${ }^{29,30}$ Then, the analysis of the variances (Anova) was performed, considering an $\alpha$ value lower than 0.05. Finally, the Tukey test was applied to compare the values of the averages obtained with each other. All the statistical analysis of the data was performed using OriginPro.

\section{RESULTS AND DISCUSSION Characterization of finished samples}

The surface morphology of the samples was analyzed by SEM. It should be noted that MPCM was relatively well dispersed on the surface of cotton when applied alone (Fig. 1a). However, Figure $1 \mathrm{~b}$ shows the formation of a few $\mathrm{TiO}_{2} \mathrm{NP}$ aggregated with $\mathrm{mPCM}$ relatively dispersed on the surface, and a thin layer of coating was formed.

When applying $\mathrm{mPCM}$ and SZ (Fig. 1c), mPCM and the chitosan film-SZ (Fig. 1d) or mPCM and the chitosan-SZ composite (Fig. 1e) to the cotton samples, some heterogeneous and relatively dispersed aggregates were observed, with higher incidence on the surface. With regard to the chitosan film-SZ and $\mathrm{mPCM}$, a slightly larger and more intense distribution on the surface of the fabric was detected. In general, the coating adheres to the surface and to the spaces between the fibers, but it is still discontinuous on the surface of the fiber.

The FTIR spectra of untreated cotton, as well as those of the different functionalized cotton samples, are shown in Figure 2. The cotton spectrum (Fig. 2a) shows characteristic peaks at $3280 \mathrm{~cm}^{-1}$ (OH groups), and an asymmetric stretching of $\mathrm{C}-\mathrm{H}$ is observed at $2900 \mathrm{~cm}^{-1}$. The adhesion of $\mathrm{mPCM}$ (Fig. 2b) is evidenced by the intensity of the absorption band in the elongation vibrations of the $\mathrm{OH}$ groups at $3280 \mathrm{~cm}^{-1}$ and $\mathrm{CH}$ at $2900 \mathrm{~cm}^{-1}$. Also, for all the $\mathrm{mPCM}$ combinations, involving the addition of radicals present in the melamine-formaldehyde microcapsules $(\mathrm{CO}-\mathrm{CH}=\mathrm{CHR})$, a small peak can be observed at $810 \mathrm{~cm}^{-1}$, which is related to the formation of Si-O-cellulose binding after the breaking of $\mathrm{Si}-\mathrm{O}-\mathrm{Si}$ groups. ${ }^{31,32}$ As for the spectrum of the cotton treated with $\mathrm{TiO}_{2}$ (Fig. 2c), the characteristic peak was not observed $(<700$ $\mathrm{cm}^{-1}$ ), since it is dominated by the spectrum of the fiber. $^{33}$

Figures $2 \mathrm{~d}, 2 \mathrm{e}$ and $2 \mathrm{f}$ show the retention of zeolites through the different applications with chitosan. All the applications implied esterification reactions. The treated samples can be compared mainly in terms of the intensity of the carbonyl peak (approximately $1730 \mathrm{~cm}^{-1}$ ) due to the esterification of the cotton fiber with citric acid. The peak at $1550 \mathrm{~cm}^{-1}$ and the $\mathrm{NH}$ bending indicate the chemical reaction between the carboxylic groups of citric acid and the amine groups of chitosan. ${ }^{34-36}$

\section{Evaluation of properties related to the thermal comfort of materials}

In this study, the thermal comfort properties of cotton fabrics finished with $\mathrm{mPCM}$ and some types of antimicrobial agents were evaluated. The samples were analyzed under stationary state conditions, evaluating the thermal conductivity, the thermal resistance and the thermal absorptivity. The permeability to air and to water vapor was also determined. 

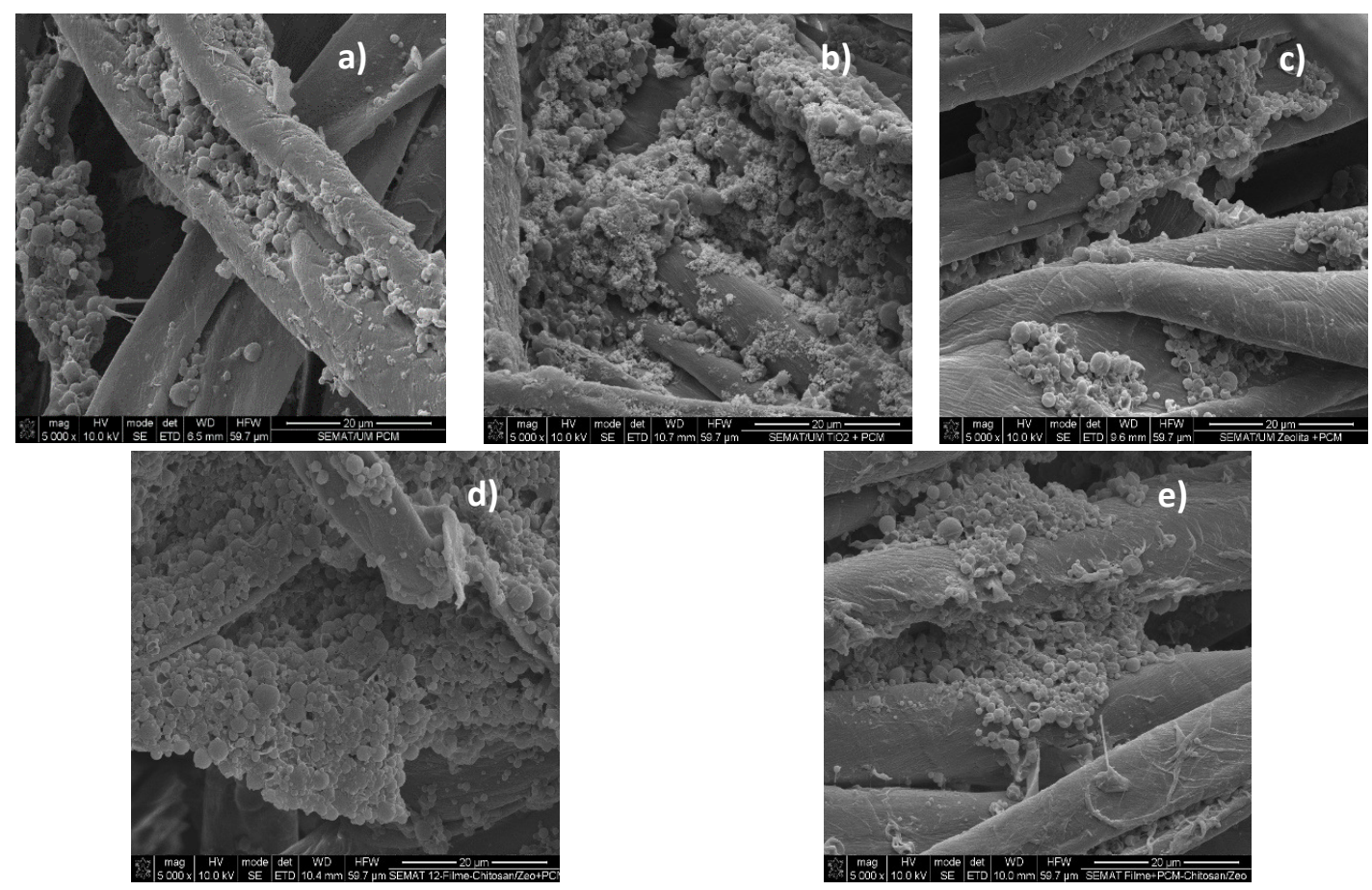

Figure 1: SEM micrographs of (a) cotton fabric treated with mPCM 5000x; (b) cotton fabric treated with mPCM and $\mathrm{TiO}_{2}$ NP 5000x; (c) cotton fabric treated with mPCM and SZ 5000x; (d) cotton fabric treated with mPCM and chitosan film-SZ 5000x; (e) cotton fabric treated with mPCM and composites of chitosan-SZ 5000x

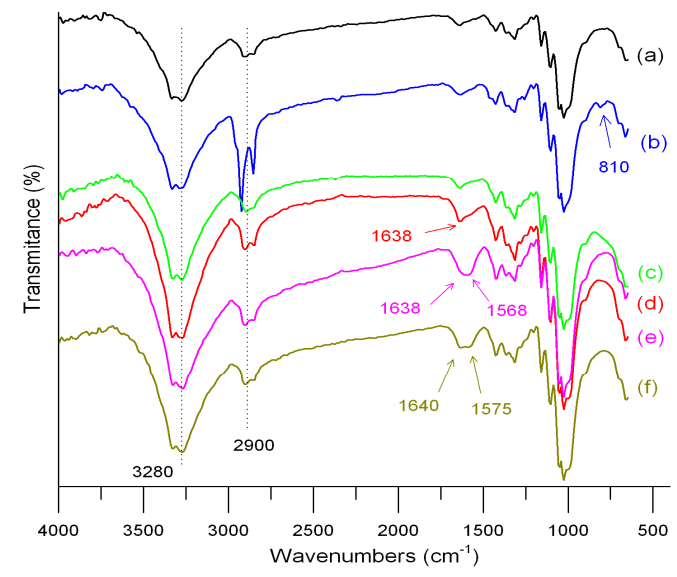

Figure 2: FTIR spectra of (a) untreated cotton fabric; (b) cotton fabric treated with mPCM; (c) cotton fabric treated with mPCM and $\mathrm{TiO}_{2} \mathrm{NP}$; (d) cotton fabric treated with $\mathrm{mPCM}$ and SZ; (e) cotton fabric treated with mPCM and chitosan film-SZ; (f) cotton fabric treated with MPCM and composites of chitosan-SZ

\section{Thermal conductivity}

The values obtained for the thermal conductivity of the finished samples are presented in Figure 3. This parameter indicates the heat conduction capability of the solid materials and is largely dependent on their structure. ${ }^{37}$ Analyzing the results obtained, it was observed that there was an increase in the thermal conductivity in all the finished samples. Considering that the basic textile material was the same, before and after the treatment, the changes registered in this property can be directly attributed to the finishes performed. It is known that the incorporation of PCM in textile materials offers thermal comfort to users. According to the statistical analysis of these results, the increase registered in the thermal 
conductivity of the functionalized samples, when compared with the standard cotton, is statistically significant for all the treatments performed, considering a level of significance of $\alpha=0.05$, as can be seen in the analysis.

When comparing the treatments with each other (Fig. 3b), it is observed that even though all the samples functionalized with MPCM presented higher thermal conductivity, the largest increase was observed in sample E. This sample was treated with the combination of MPCM with the chitosan film with silver doped zeolites, but without statistically significant differences when compared with samples F, D and C, which correspond to the treatments with the combination of $\mathrm{mPCM}$ with chitosan-zeolite composites, mPCM with silver doped zeolites and mPCM with $\mathrm{TiO}_{2}$ nanoparticles, respectively.

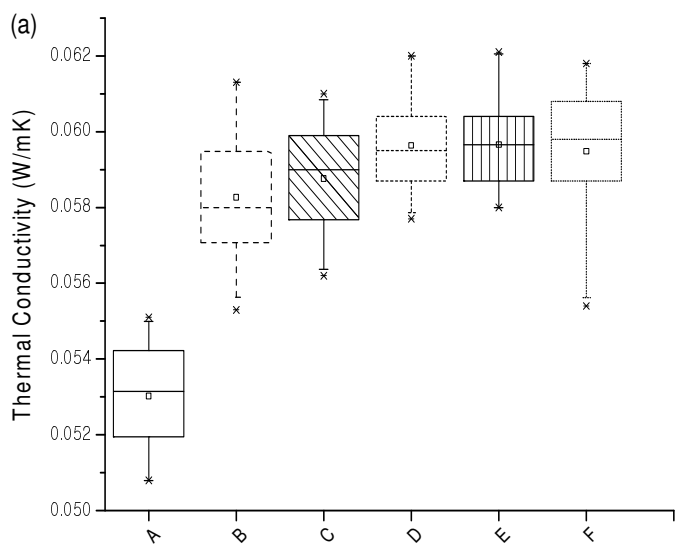

\section{Thermal resistance}

The thermal resistance of the samples is shown in Figure 4. The differences concerning the thermal resistance registered between the treated samples and the untreated sample were statistically significant, considering a level of significance $\alpha=0.05$. However, the samples treated with the combination of $\mathrm{MPCM}$ with silver doped zeolites (D), mPCM with the chitosan film with silver doped zeolites (E), mPCM with composites of chitosan-zeolite $(\mathrm{F})$, as well as the samples treated with $\mathrm{mPCM}$ alone (B), did not present statistically significant differences. Sample C presented the best performance regarding this parameter.

Figure 3: (a) Average values of thermal conductivity of the samples; (b) Difference of averages of thermal conductivity between pairs of samples
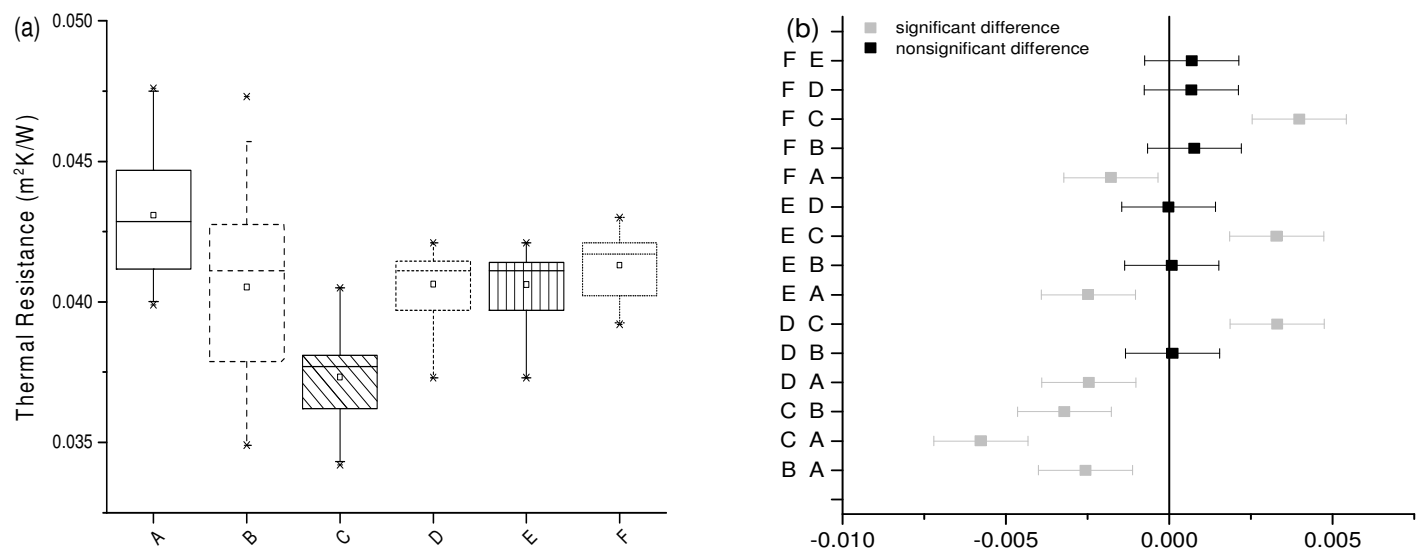

Figure 4: (a) Average values of thermal resistance of the samples; (b) Difference of averages of thermal resistance between pairs of samples 
Thermal resistance is one of the most important properties for measuring the heat retention capability of materials. ${ }^{4}$ Materials with higher thermal resistance allow a minimization of heat loss between the body and the environment, since the heat transfer occurs more slowly. ${ }^{38}$ The presence of the mPCM on the cotton seemed to facilitate the heat dissipation and the finished materials presented lower thermal resistance when compared with the samples without finish. ${ }^{39}$

\section{Thermal absorptivity}

Thermal absorptivity is the parameter that allows to draw conclusions about the sensation of heat/cold provided upon first contact with the materials. $^{7,40}$ Thus, high values of thermal absorptivity mean that the fabrics may suggest a fresh touch feeling. Nevertheless, this property is also related to the structure and composition of the fabric. ${ }^{41}$

The results obtained concerning the thermal absorptivity of the samples tested are presented in Figure 5, showing that the different treatments present statistically different average results, considering a level of significance $\alpha=0.05$, when compared with each other, except for the samples treated with $\mathrm{mPCM}$ combined with silver doped zeolites (D), mPCM combined with the chitosan film with silver doped zeolites (E) and the samples treated with chitosan-zeolite composites (F). Thus, in general, it can be stated that the treated samples provide a fresher touch than the untreated ones.

The finish of the materials can influence the thermal absorptivity whenever a change occurs in

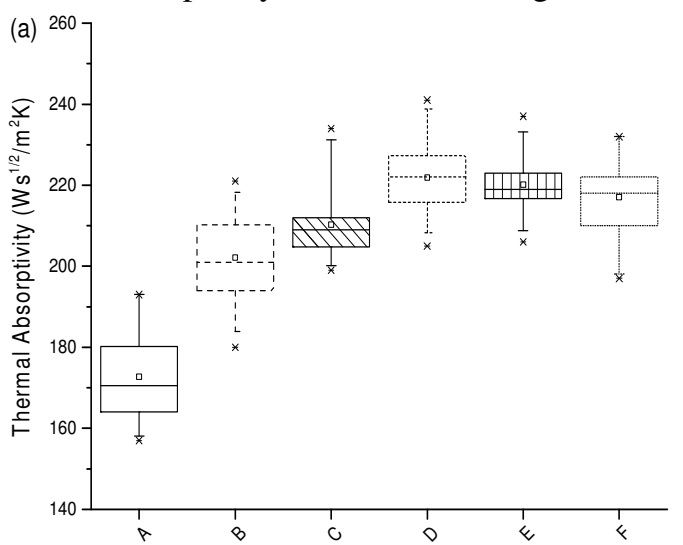

its surface. This can happen, for example, if there is an increase in roughness. ${ }^{42}$ In this case, the contact between the surfaces will occur through micro-zones of contact, which represent only a fraction of the total surface area of the materials. Considering neither the interstitial fluid nor the transfer of heat by radiation, the energy transfer will occur only through micro-zones of contact, directly conditioning the heat flow that may occur when the materials establish contact with each other. The increase in the contact area, in turn, allows a greater amount of heat to pass through the fabric, producing, consequently, a greater sensation of freshness when the contact with its surface occurs. ${ }^{40}$ Therefore, the regularity of the surface of the functionalized material will influence its thermal properties. The finished samples, when compared with the untreated cotton samples, presented higher conductivity and absorptivity and lower thermal resistance, modifying their properties. This type of influence had also been described by Alay et al., ${ }^{5}$ Onofrei et al.,${ }^{39}$ Abreu et al. ${ }^{41}$ and Hes et al. ${ }^{43}$

\section{Water vapor permeability}

The humidity management of a textile material is an indicator of the level of comfort it confers. The permeability to water vapor is essential for the sensation of comfort, since it facilitates the evaporation of sweat from the skin surface, easing up the mechanism of thermal self-regulation of the human body. ${ }^{38}$

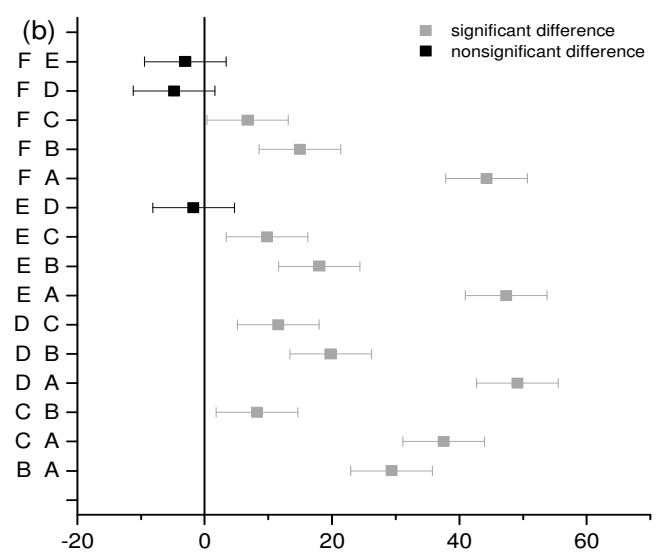

Figure 5: (a) Average values of thermal absorptivity of the samples; b) Difference of averages of thermal absorptivity between pairs of samples 

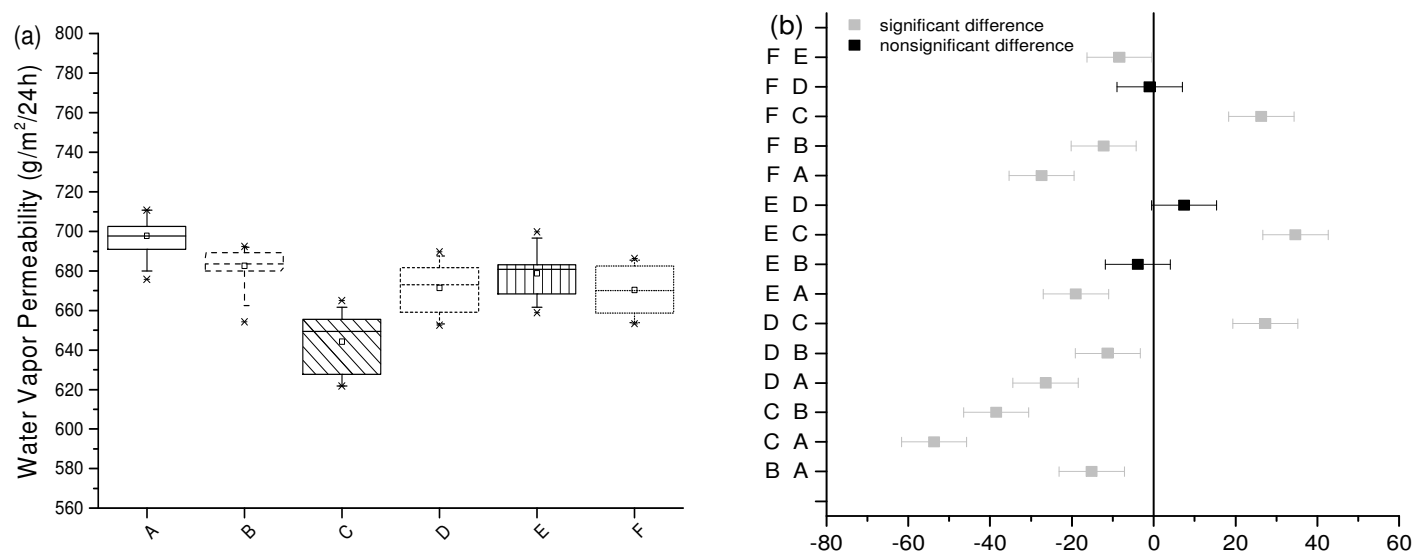

Figure 6: (a) Average values of water vapor permeability of the samples; (b) Difference in the averages of water vapor permeability between pairs of samples

The results obtained concerning the water vapor permeability of the samples are shown in Figure 6 . All the functionalized samples showed a slight decrease in the water vapor permeability when compared with the untreated cotton. The permeability to water vapor is one of the properties of the materials that can be altered through the finishes. ${ }^{38}$ In this case, the treatments acted as a coating that blocked the pores of the material. Thus, the addition of $\mathrm{mPCM}$ and other surface finishing agents had direct influence on these results. This has already been observed by other researchers when applying $\mathrm{mPCM}$ in the functionalization of materials. ${ }^{44}$

All the average values are significantly different, at a significance level $\alpha=0.05$, when compared with the control samples. Comparing the finished materials with the untreated sample, it could be noted that sample B (treated with $\mathrm{mPCM}$ alone) presented the greatest proximity to the untreated samples, in terms of average value for the water vapor permeability of the samples. This can be explained by the fact that the recoating of the surface was smaller due to the characteristics of the finish. On the other hand, the samples treated with $\mathrm{mPCM}$ and $\mathrm{TiO}_{2} \mathrm{NP}$ (sample C) presented the lowest value of permeability to water vapor after the finishing process.

When compared with each other, the pairs of samples treated with $\mathrm{mPCM}$ alone (B) and samples treated with $\mathrm{MPCM}$ combined with the chitosan film with zeolites (E), the samples treated with $\mathrm{mPCM}$ combined with silver doped zeolites (D) and the samples treated with $\mathrm{mPCM}$ combined with the chitosan film with zeolites (E), as well as the samples treated with $\mathrm{mPCM}$ combined with silver doped zeolites (D) and the samples treated with $\mathrm{MPCM}$ combined with chitosan-zeolite composites (F), did not present statistically significant differences between them.

\section{Air permeability}

Figure 7 shows the results concerning the air permeability of the treated materials and of the control sample. The fact that the finishing agents applied on the materials may cover their pores can contribute to a decrease in air permeability. This is reflected in a statistically significant decrease in the air permeability indexes observed for the functionalized samples.

The values presented statistically significant differences between them, considering a level of significance $\alpha=0.05$. When compared with each other, the samples evaluated showed statistically significant differences concerning the air permeability index, except for sample $F$, treated with $\mathrm{mPCM}$ combined with chitosan-zeolite composites, when compared with sample D, corresponding to the finish comprising $\mathrm{mPCM}$ combined with silver doped zeolites. The finish that most compromised the breathability of the material was the one that used MPCM combined with $\mathrm{TiO}_{2}$ nanoparticles (sample C). In this finish, the pore re-coating effect may have been more efficient and, consequently, the permeability to air has been more compromised. 

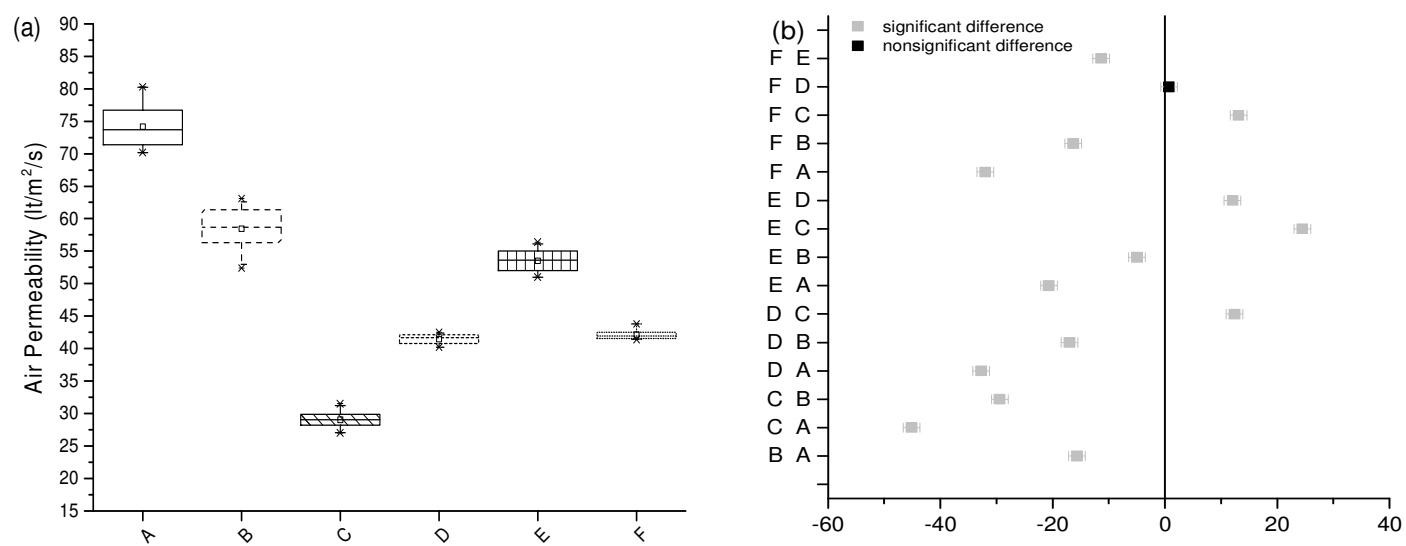

Figure 7: (a) Average values of air permeability of the samples; (b) Difference in the averages of air permeability between pairs of samples

The lower the air permeability is, the greater the discomfort resulting from sweating will be. ${ }^{45}$ This parameter is also closely related to the permeability to water vapor and, together, they determine the capability of humidity management of the material. In addition, there is an inverse proportionality with thermal resistance, as reported by Slater. ${ }^{4}$

\section{CONCLUSION}

Multifunctional cotton samples were developed through different finishing approaches involving the application of $\mathrm{mPCM}$ conjugated with different antimicrobial agents. From the statistical analysis of the results obtained regarding thermal properties and moisture management, the following conclusions can be drawn.

- All the samples showed changes in their properties, most directly related to thermal comfort. They exhibited higher thermal conductivity, higher thermal absorptivity and lower thermal resistance, being therefore cooler to the touch than standard cotton. This behavior was caused by the presence of MPCM in the materials, but was also influenced by the other finishing agents. The samples that combined MPCM with silver doped zeolites, with the chitosan film with zeolites, and, also, with chitosan-zeolite composites obtained a better performance, without a statistically significant difference with regard to thermoregulatory behavior.

- The finishing processes resulted in a decrease in the permeability of materials to air and water vapor. The quality of the coating, in terms of recoating efficiency and penetration into the pores of the material, has determined difficulties in the dissipation of water vapor and air. In the present study, the application of $\mathrm{TiO}_{2}$ nanoparticles with the MPCM was the finish that most negatively influenced the properties of humidity management. On the other hand, the finishes with the addition of $\mathrm{mPCM}$ alone or combined with MCT- $\beta-C D$ obtained a permeability behavior closer to that of the samples without functionalization.

- Overall, the finish that presents a better compromise in terms of the studied properties is the combination between mPCM and the chitosan film with silver doped zeolites, since it has a slightly higher performance in terms of the properties studied.

However, it should be noted that, even though the work done allows comparing the different finishes regarding the properties studied, it would be highly desirable to deepen the analysis of the comfort conferred by these materials through other tests that simulate the real conditions of use. In this sense, it would be interesting to evaluate a piece made from these materials using a thermal manikin.

ACKNOWLEDGMENTS: The authors acknowledge CNPq-Brazil (Conselho Nacional de Desenvolvimento Científico e Tecnológico Brasil/National Council of Scientific and Technological Development - Brazil) for the doctoral scholarship (233550/2014-3). This work has been also financed by Project UID/CTM/00264/2019 of 2C2T - Centro de Ciência e Tecnologia Têxtil, funded by National Founds through FCT/MCTES. 


\section{REFERENCES}

K. Slater, "Human Comfort", Thomas Sprinfield, USA, 1985.

2 K. L. Hatch, "Textile Science", West Publishing Company, USA, 1993.

3 Y. Li, Text. Prog., 31, 1 (2001), https://doi.org/10.1080/00405160108688951

4 K. Slater, J. Text. Inst., 77, 157 (1979).

5 S. Alay, C. Alkan and F. Göde, J. Text. Inst., 103, 757 (2012), DOI: 10.1080/00405000.2011.606982

6 S. Kawabata and Y. Akagi, J. Text. Mach. Soc. Japan, 23, 51 (1977).

7 L. Hes and I. Dolezal, Coll. Mech. Text. Eng., 42, 71 (1989).

8 S. Mondal, Appl. Therm. Eng., 28, 1536 (2008), https://doi.org/10.1016/j.applthermaleng.2007.08.009

9 E. Onofrei, A. M. Rocha and A. Catarino, Bul. Inst. Polit. Iasi, $\quad \boldsymbol{L X}, \quad 109 \quad$ (2010), http://www.tex.tuiasi.ro/BIP/2_2010/99-

110_12_Onofrei_PCM_.pdf

10 S. X. Wang, Y. Li, J. Y. Hu, H. Tokura and Q. W.

Song, Polym. Test., 25, 580 (2006), https://doi.org/10.1016/j.polymertesting.2006.01.018

11 Y. Shin, D. I. Yoo and K. Son, J. Appl. Polym. Sci., 97, 910 (2005), https://doi.org/10.1002/app.21846

12 M. I. H. Mondal and J. Saha, J. Polym. Environ., 27, 405 (2019), https://doi.org/10.1007/s10924-0181354-9

13 M. Hartmann, J. G. Dolan and A. Eyal, Patent WO2007/130709, 2007.

14 I. Cardoso and J. N. R. Gomes, Int. J. Cloth. Sci. Technol, $\quad \mathbf{2 1}, \quad 102 \quad$ (2009), https://doi.org/10.1108/09556220910933826

15 D. Celcar, J. Text., 2013, 1 (2013).

16 K. Iqbal and D. Sun, Fibers Polym., 16, 1156 (2015), https://doi.org/10.1007/s12221-015-1156-9

17 Y. Gao and R. Cranston, Text. Res. J., 78, 60 (2008), https://doi.org/10.1177/0040517507082332

18 F. Zhang, X. Wu, Y. Chen and H. Lin, Fibers Polym., 10, $496 \quad$ (2009), https://doi.org/10.1007/s12221-009-0496-8

19 D. S. Morais, R. M. Guedes and M. A. Lopes, $\begin{array}{lllll}\text { Materials } & \text { (Basel)., } & 9, & 1 & \text { (2016), }\end{array}$ https://doi.org/10.3390/ma9060498

20 J. Milanović, K. Mihajlovski, T. Nikolić and M. Kostić, Cellulose Chem. Technol., 50, 905 (2016), http://www.cellulosechemtechnol.ro/pdf/CCT910(2016)/p.905-914.pdf

21 J. Kim, M. Gong and J. Kim, Cellulose Chem. Technol., $\quad \mathbf{5 2 ,} \quad 475 \quad$ (2018), http://www.cellulosechemtechnol.ro/pdf/CCT56(2018)/p.475-484.pdf

22 Y. Yi, Y. Wang and H. Liu, Carbohyd. Polym., 53, $425 \quad$ (2003), https://doi.org/10.1016/S01448617(03)00104-8

23 S. Chen, G. Wu and H. Zeng, Carbohyd. Polym., 60 33

(2005),
24 W. L. Du, S. S. Niu, Y. L. Xu, Z. R. Xu and C. L. Fan, Carbohyd. Polym., 75, 385 (2009).

25 P. H. Yassue-Cordeiro, C. H. Zandonai, C. F. Silva and N. R. C. Fernandes-Machado, Polímeros, 25, 492 (2015), doi:10.1590/0104-1428.2059

26 F. A. P. Scacchetti, E. Pinto and G. M. B. Soares, Prog. Org. Coatings, 107, 64 (2017), https://doi.org/10.1016/j.porgcoat.2017.03.015

27 F. A. P. Scacchetti, E. Pinto and G. M. B. Soares, IOP Conf. Ser. Mater. Sci. Eng., 254, 122011 (2017).

28 F. A. P. Scacchetti, E. Pinto and G. M. B. Soares, Procedia Eng., 200, 276 (2017).

29 S. M. Callegari-Jacques, "Bioestatística Princípios E Aplicações", Artmed Editora, Porto Alegre, 2003.

30 A. Hall, C. Neves and A. Pereira, "Grande Maratona de Estatística no SPSS", Escolar Editora, 2011.

31 J. I. N. R. Gomes, R. M. M. V. Vieira and S. M. P. C. B. Barros, US Patent 8,404,345 B2, 2006.

32 Y. Wang, J. Macromol. Sci., 50, 1739 (2011), https://doi.org/10.1080/00222348.2010.549051

33 M. J. Uddin, F. Cesano, F. Bonino, S. Bordiga, G. Spoto et al., J. Photochem. Photobiol. A Chem., 189, 286

(2007), https://doi.org/10.1016/j.jphotochem.2007.02.015

34 S. B. Vukušić, S. F. Grgac, D. Katović and A. Katović, Mater. Sci. Forum, 700, 203 (2011), doi:10.4028/www.scientific.net/MSF.700.203

35 N. M. Morris, E. A. Catalano and B. A. K. Andrews, $\quad$ Cellulose, 2, $31 \quad$ (1995), https://doi.org/10.1007/BF00812770

${ }^{36}$ Z. Yang, Z. Zeng, Z. Xiao and H. Ji, Flavour Fragr. J., 29, 114 (2014), doi:10.1002/ffj.3186.

37 M. M. Mangat, L. Hes and V. Bajzik, Text. Res. J.,

85 , 200

(2014),

https://doi.org/10.1177/0040517514545254

38 K. Slater, Text. Prog., 77, 1 (1977).

39 E. Onofrei, A. M. Rocha and A. Catarino, J. Eng. Fibres Fabr., $\quad$ 6, $10 \quad$ (2011), https://pdfs.semanticscholar.org/f9ce/ea2e932e1406f3b b71d65d3bdf963e40b43f.pdf

40 A. Mangat, L. Hes and V. Bajzik, Autex Res. J., 1, 6 (2016).

41 I. Abreu, P. Ribeiro and M. Abreu, in Procs. $7^{\text {th }}$ International Textile, Clothing \& Design Conference Magic World of Textiles, Dubrovnik, October 5-8, 2014, pp. 1-7.

42 M. M. Yovanovich and W. M. Rohsenow, "Influence of Surface Roughness and Waviness upon Thermal Contact Resistance", Technical Report, Massachusetts, 1984.

43 L. Hes and B. I. Lu, RJTA, 8, 51 (2004), https://doi.org/10.1108/RJTA-08-02-2004-B007

44 H. Chung and G. Cho, Text. Res. J., 74, 571 (2004), https://doi.org/10.1177/004051750407400702

45 C. Gao, in Procs. Scientific Conference on Smart and Functional Textiles, Tampere, September 7-9, 2014, pp. 1-7. 